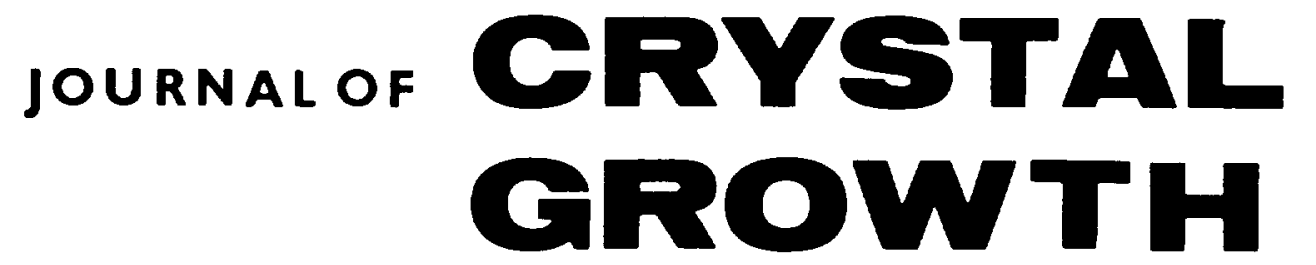

Magneto-hydrodynamic damping of convection during vertical Bridgman-Stockbarger growth of $\mathrm{HgCdTe}$

D.A. Watring ${ }^{*}$, S.L. Lehoczky

Space Sciences Laboratory. NASA Marhall Space Flight Center, Huntsille. Alabama 35812. USA

Received 3 April 1995; accepted 26 January 1996

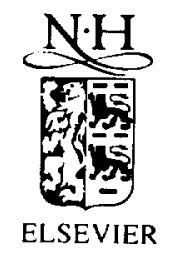




\section{Journal of Crystal Growth}

\section{EDITORIAL BOARD}

M. SCHIEBER (Principal Editor)

Depr. Mater. Sci.. School Appl. Sci. \& Technol.

Hebrew University, Jerusalem 91904, Israel

Telefax: $+972-2-666804$

R. KERN

CRMC ${ }^{2}$, CNRS, Campus Luminy, Case 913

F.13288 Marseilic Cedex 9. France

Telefax: + 33-91-418916

\author{
R.S. FEIGELSON \\ Crr. Materials Res. $105 \mathrm{McCullough} \mathrm{Bldg.}$ \\ Stanford Univ., Stanford, CA 94305-4045, USA \\ Telefax: + ]-415-723 3044 \\ T. NISHINAGA \\ Deph. Electron. Eng.. Univ. of Tokyo \\ 7-3-1, Hongo, Bunkyo-ku, Tokyo 113, Japan \\ Telefax: $+81-3-5684-3974$
}

\section{ASSOCIATE EDITORS}

A. BARONNET (Industrial, Biological. Molecular Crystals) CRMC: CNRS, Campus Luminy, Case 913

F. 13288 Marseille Cedex 9. France

Telefax + 33-91-418910

K.W. BENZ (Microgravity, Electronic Materials)

Kristallographisches Inst. Universitat

Hebelstr. 25. D-79104 Freiburg, Germany

Telefax: +49-761-2034369

A.A. CHERNOV (Kinetics of Crystallization.

Protein Crystallization

Inst. Crystallography, Acad. of Sriences

Leninskii Prosp., Moscow 117333, Russian Fed.

Telefax: + 7-095-135 1011

A.Y. CHO (Molecular Beam Epilaxy)

Room IC -323, AT\& T Bell Laboratories

Murmay Hill, NJ 07974-2070. USA

Telefax: + - -908-582 2043

B. COCKAYNE (IOCG New's)

School of Metallurgy and Mater.

Univ. Bimingham, P.O. Box 363, Edgbaston, Birmingham

B15 2TT. UK

Telefax: $+44-121-4712207$

S.R. CORIELL (Theory)

A 153 Mater, Natl Inst. of Standards \& Technot

Gaichersburgh. MD 20899-0001, USA

D. ELWELL (Priority Communications. Superconductivity

Hughes Aircraft Company

P.O. Box H. M'S A2408, 500 Superior Avenue

New Pon Beach. CA 92658-8908. USA

Telefax: + +.714.759 2868

M.E. GLICKSMAN (Solidificution)

School of Eng.. Mater. Eng. Dept., Rensselacr Polytechnic

Inst. Troy. NY $12180-3590$, USA

Telefax: $+1-518-2768554$

M.A.G. HALLIWELL ( $X$-ray Diffraction)

Philips Analytical X-ray, Lelyweg

7602 EA A Imelo, The Netherlands
T. HIBIYA (Oxides. Melt Thermophysical Properties. Microgravity)

Fundamental Res. Labs., NEC CORPORATION

34. Miyukigaoka, Tsukuba 305, Japan

Telefax: $+81 \cdot 298-566136$

H. KOMATSU (Proleins Molecular Crystallization. Growth from Solutions

Inst. Mater. Res. Tohoku Uniy.

Katahira 2-1-1. Sendai 980. Japan

Telefax: $+81-22-2152011$

TF. KUECH (Thin Films and Elecironic

and Optical Devices

Dept. Chem. Eng.. Univ. Wisconsin-Madison

Madison, WI 53706. USA

Telefax: $+1-608-2653782$

A. MCPHERSON (Protein Growth)

Dept. Biochemistry, Univ. of Califomia

Riverside, CA 92521, USA

Telefax: $+1-909-7873790$

P.A. MORRIS HOTSENPILLER (Electrooptical Crystals, Book Reviews, Oxide Thin Films)

E.I. du Pont de Nemours \& Co. Exp. Station

Wilmington. DE 19888-0358. USA

Telefax: + 1.302-695 1664

J.B. MULLIN (Semiconductors)

EMC. "The Hoo", Brockchill Roa

West Malverm. Worcs.. WR 144 DL, UK

Telefax: +44-1684-575 591

K. NAKAJIMA (Liquid and Vapor Phase Epitary)

Integrated Mater. Lab., Fujitsu Labs. Ltd.

Morinosato-Wakamiya 10-4. Atsugi 243-01. Japan

Telefax: $+81.462-483473$

H. OHNO (Epilaxy)

Rescarch Inst. of Electrical Commun.

Tohoku liniv. Sendai 98077 . Japan

Telefax: $+81-22-217555$

K. PL.OOG (Molccular Beam Epiary)

Paul-Dnude-Inst. für Festkörperelektronik

Hauswogleiplatz 5-7. D- 10117 Berlin. Germany

Telefax: $+49 \cdot 30-20377201$
D.TJ. HURLE

H.H. Wills Phys. Lab., Univ. Bristol

Tyndalt A venue

Bristol BS8 1TL. UK

G.B. STRINGFELLOW

Dept. Mater. Sci., 304 EMRO. Univ. of Utah

Salt Lake City, UT 84112, USA

Telefax: +1.801 .5814816$
F. ROSENBERGER (Prolein Crystallization. Fluid Dynamics)

Center for Microgravity and Materials Research

Univ. A labama. Huntsville. AL 35899, USA

Telefax: +1-205-895 6791

R.W. ROUSSEAU (Solution Growth.

Industrial Crystallizution)

School of Chem. Eng., Georgia Inst. of Technol.

Atlanta, GA 30332-0100, USA

Telefax: + 1-404-8942866

K. SATO (Bircrystalization and

Organic Crystals)

Fac. Appl. Biol. Sci., Hiroshima Univ.

Higashi-Hiroshima 724, Japan

Telefax: +81-824-227 062

\section{F. SCHNEEMEYER (Superconductivity. \\ Oxides. Novel Materials \\ Room IA-363, AT\&T Bell Labs. \\ Murray Hill, NJ 07974-2070, USA \\ Telefax: +1-908-582 252}

D.W. SHAW (Semiconductors, Epilaxy, Devices) Texas Instruments [nc.. P.O. Box 655936, MS 14]

Dallas. TX 75265, USA

Telefax: +1-214-995 7785

I. SUNAGAWA (Minerals)

3-54-2 Kashiwa-cho, Tachikawa-sh

Tokyo 190. Japan

Telefax: $+81-425-353637$

G. VAN TENDELDO (Electron Microsconpy.

Fullerenes. Superconductivity)

Universiry of A

Universily of Aniwerp, RUCA

Groenenborgerlaan 171, B-2020 Antwerp, Belgium

Telefax: +32-3-2180 217

A.F. WITT (Semiconductor Crystals)

Dept. of Metall. \& Mater. Sci.. Massachusetts

Inst. of Technol., Cambridge, MA 02139, USA

Telefax: $+1-617.2535827$

A. ZANGWILL (Theory (Epiary))

School of Physirs, Georgia Inst. of Technol.

Atlanta, GA 30332, USA

Telefax: + 1-404-894 9958
Scope of the Journal

Experimental and theoretical contributions are invited in the following fields: Theory of nucleation and growth, molecular kinetics and transport phenomena, crystallization in viscous media such as polymers and glasses. Crystal growth of metals, minerals, semiconductors, magnetics, inorganic, organic and biological substances in bulk or as thin films. A pparatus, instrumentation and techniques for crystal growth, and purification methods. Characterization of single crystals by physical and chemical methods.

Abstracted/Indexed in:

Aluminium Industry Abstracts; Chemical Abstracts; Current Contents: Physical, Chemical and Earth Sciences: El Compendex Plus: Engineered Materials Abstracts: Engineering Index; INSPEC; Metals Abstracts; Physics Briefs.
Subscription Information 1996

Volumes 158-169 of Joumal of Crysial Growth (ISSN 0022-0248) are scheduled for publication. (Frequency: semimonthly.) Prices are available from the publishers upon request. Subscriptions are accepted on a prepaid basis only. Issues are sent by SAL (Surface Air Lifted) mail wherever this service is available. Airmail rates are available upon request. Please address all enquiries regarding orders and subscriptions to:

Elsevier Science B.V.. Onder Fulfilment Department

P.O. Box 211,1000 AE Amsterdam, The Netherlands

Tel: $+31204853642 ;$ Fax $:+3 ! 204853598$

Claims for issues not received should be made within six months of our publication (mailing) date.

US mailing notice - Journal of Crystal Growth (ISSN 0022-0248) is published semimonthly by Flsevier Science B.V.. Molenwerf I, P.O. Box 211 , 1000 AE Amsterdam. The Necherlands. Annual subscription price in the USA is US $\$ 6535$ (valid in North, Central and South America only), including air speed delivery. Periodicals postage paid at Jamaica NY 11431.

LS postmasters: Send address changes to Joumal of Crystal Growth. Publications Expediting. Inc., 200 Meacham Avenue. Elmont NY 11003 . Airfeight and mailing in the liSA by Publications Expediting.

The paper used in this publication meets the requirements of ANSU/NISO 2.39.48-1992 (Permanence of Paperi

PRINTED IN THE NETHERLANDS

North-Holland, an imprint of Elsevier Science 


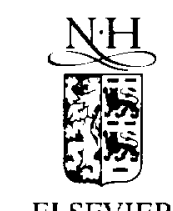

ELSEVIER

Journal of Crystal Growth $167(1996) 478-487$

\title{
Magneto-hydrodynamic damping of convection during vertical Bridgman-Stockbarger growth of $\mathrm{HgCdTe}$
}

\author{
D.A. Watring * , S.L. Lehoczky \\ Space Sciences Laboraton, NASA Marshall Space Flight Center, Huntsille. Alabama 35812. USA
}

Received 3 April 1995; accepted 26 January 1996

\begin{abstract}
In order $t 0$ quantify the effects of convection on segregation. $\mathrm{Hg}_{0.8} \mathrm{Cd}_{0.2} \mathrm{Te}$ crystals were grown by the vertical Bridgman-Stockbarger method in the presence of an applied axial magnetic field of $50 \mathrm{kG}$. The influence of convection, by magneto-hydrodynamic damping, on mass transfer in the melt and segregation at the solid-liquid interface was investigated by measuring the axial and radial compositional variations in the grown samples. The reduction of convective mixing in the melt through the application of the magnetic field is found to decrease radial segregation to the diffusion-limited regime. It wals also found that the suppression of the convective cell near the solid-liquid interface results in an increase in the slope of the diffusion-controlled solute boundary layer, which can lead to constitutional supercooling.
\end{abstract}

\section{Introduction}

For nearly four decades, the usefulness of applied magnetic fields in crystal growth from the melt has been recognized. The fundamental basis for the interaction between magnetic fields and convection was first discussed in Refs. [1-5]. The basic mechanism for the interaction of an applied magnetic field and a molten semiconductor involves the electrical currents induced by the movement of a conductor in the presence of a magnetic field. Early experiments by Utech and Flemings [6.7] investigated the effects of a magnetic field on tellurium-doped indium antimonide grown in a horizontal furnace by directional solidification. Their results indicated that vertical

Corresponding author. magnetic fields of 1300 and $1750 \mathrm{G}$ were sufficient to suppress turbulence in the melt. This eliminated the temperature fluctuations which caused melting and resolidification of the growth interface and an associated fluctuation in the dopant concentration in the crystal grown in zero field.

Temperature and solutal gradients in the melt during growth almost always result in buoyancydriven convection. Frequently, this convective flow is oscillatory [8] and gives rise to a fluctuating rate of crystal growth, which, in turn, produces a microscopically non-uniform distribution of dopant in the crystal. The universal effect of an applied magnetic field is the damping of the convective turbulence in the melt, which produces a more homogenous dopant distribution [9-13].

The majority of the experimental studies with magnetic fields has been focused on the growth of $\mathrm{GaAs}, \mathrm{Si}$ and Ge by the Czochralski growth process. 

In these systems, small $(2-5 \mathrm{kG})$ fields were applied to suppress turbulent convection. Limited work $[6,12-16]$ has been conducted on the magnetic effects of crystal growth in a vertical BridgmanStockbarger configuration and out of these experiments only two involved the II-VI compounds of $\mathrm{HgCdTe}$ and $\mathrm{HgZnTe}$.

The Hg-based II-VI semiconductor compounds are important for application of infrared detection and imaging applications for a broad range of wavelengths from $0.8 \mu \mathrm{m}$ to the far-infrared spectrum beyond $30 \mu \mathrm{m}$. The crystal growth of these $\mathrm{Hg}$-based II-VI systems is characterized by a destabilizing horizontal temperature gradient due to a difference in the thermal conductivities of the melt and the crystal at the growth interface in the presence of a containing crucible and the release of latent heat. Additionally, a stabilizing vertical solutal gradient is produced by the rejection of the denser constituent (HgTe in the case of $\mathrm{HgCdTe}$ ) into the melt. These phenomena, coupled with a large solutal-to-thermal expansion coefficient ratio $\left(\beta_{\mathrm{c}} C_{0} / \beta_{1} \Delta T_{\mathrm{r}} \approx 100\right)$ and a large thermal-to-solutal diffusion coefficient ratio $\left(\alpha_{\mathrm{T}} / D_{\mathrm{L}} \approx 200\right.$ ), give rise to double diffusive convection during the growth of these binary semiconductors, where $\Delta T_{\mathrm{r}}$ is the radial temperature difference, $C_{0}$ is the starting composition, $\beta_{\varepsilon}$ and $\beta_{1}$ are, respectively, the solutal and thermal expansion coefficients and $\alpha_{\mathrm{T}}$ and $D_{\mathrm{l}}$, are the thermal and solutal diffusion coefficients, respectively. If this buoyancy-induced convection is large as compared to the solidification velocity, it can interfere with segregation near the solid-liquid interface resulting in a non-homogenous crystal. It is believed that the reduction of convection should be advantageous in maintaining the solid-liquid interface shape required to minimize the crystal defect densities while minimizing compositional variation transverse to the crystal growth direction.

This paper focuses on the influence of the magnetic field on mass transfer in the melt and radial segregation at the solid-liquid interface. We begin with a description of the charge crucible configuration, followed by a brief discussion of the Bridgman-Stockbarger growth system used for the experiments. Results of the axial and radial compositional distributions with and without the presence of the magnetic field are, then, described.

\section{Experimental procedure}

\subsection{Sample preparation}

The starting materials were triple-distilled instrument grade $\mathrm{Hg}$ from Bethlehem Apparatus and six nines grade $C d$ and $T e$ from Johmson Matthey. The ampoules were made from $8 \mathrm{~mm}$ ID $\times 12 \mathrm{~mm}$ OD commercial grade. T08, fused silical quartz. A tapered section was formed on the quartz ampoule to enhance the probability of single erystal growth. An internal layer of graphite was formed on the ampoule as described in Ref. [16] to prevent the adhesion of HgCdTe to the ampoule walls. The elements were weighed out for $\mathrm{Hg}_{1}, \mathrm{Cd}_{1} \mathrm{Te}(x=0.2)$. loaded into the ampoules and sealed off under a $10^{+}$Torr vacuum. The $\mathrm{Hg}_{0.8} \mathrm{Cd}_{1.2} \mathrm{Te}$ ingols were compounded by a homogenization process that has been described in detail elsewhere [16]. The formed ingots were 14 cm long and weighed approximately 47 :

\subsection{Directional solidification growth srstem}

The ingots were regrown by directional solidificattion in the presence of a stationary axially aligned magnetic field as shown schematically in Fig. la. The Bridgman-Stockbarger crystal growth system consisted of five heated zones with the booster and cold zone separaled by a $2 \mathrm{~cm}$ adiabatic zone. A 0.3 cm thick heat extraction plate was placed helween the adiabatic zone and cold zone to produce high axial gradients. The ampoule was supported by an inconel 625 cartridge assembly shown in Fig. Ih and remained stationary during erystal growth. Translating the furnace instead of the cartridge minimized any movement and vibrations of the sample and allowed the crystallization to take place in the homogenous region of the magnetic field. The superconducting magnet is manually set to the desired field strength (up to $50 \mathrm{kG}$ ) and is held constant during the entire growth process. The thermal profile was chosen in order to produce a gradient of approximately $80^{\circ} \mathrm{C} / \mathrm{cm}$ on the ampoule wall at the position of $706^{\circ} \mathrm{C}$. the solidus temperature for the steady-state growth [17]. The themal profile was translated at at relatively slow rate of $0.2 \mu \mathrm{m} / \mathrm{s}$ in order to avoid constitutional supercooling [ 18$]$. 


\subsection{Characterization}

The effect of convection on segregation was determined by measuring radial and axial compositional variations in the grown crystals. For this study, the average $x$ values ( $x$ is the mole fraction of $\mathrm{CdTe}$ ) of wafers cui transverse to the growth direction were determined by high precision density determinations and the values of the crystal lattice constant published by Woolley and Ray [19] as described in detail elsewhere $[20,21]$.
For $x$ values of 0.18 or larger, the radial microdistribution of cadmium telluride was quantitatively determined from the transmission edge of the IR transmission spectrum. The details of this highly automated transmission-edge mapping technique are described in Ref. [22]. Briefly, the hardware consists of a Fourier transform spectrometer specially equipped with a software controllable $x y$ stage driven by stepper motors. The stage can position the sample throughout a $2.54 \mathrm{~cm}$ square in $50 \mu \mathrm{m}$ steps. Spectra are then analyzed to obtain the cut-on wavelength
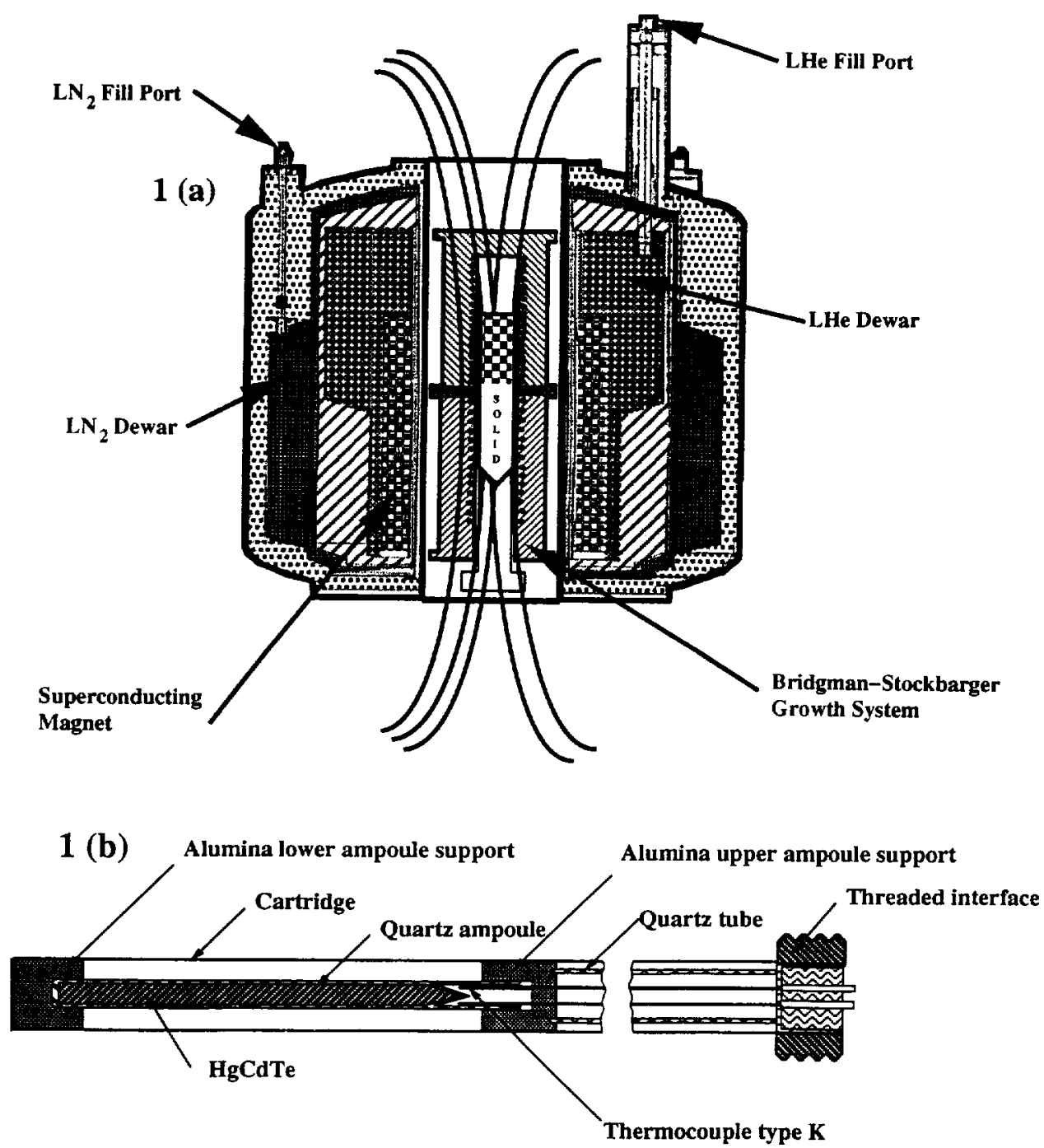

Fig. 1. (a) Schematic representation of the magnetic Bridgman-Stockbarger growth system. (b) Containment cartridge utilized for the magnetically stabilized growth of $\mathrm{HgCdTe}$. 
and the mole fractions of $\mathrm{CdTe}$ are calculated from the compositional dependence of the energy bandgap. For those samples with a cadmium telluride content of less than $x=0.18$, the radial compositional variations were determined by energy dispersive $\mathrm{X}$-ray spectroscopy analysis (EDX) using pseudo-binary solid solutions as standards [23].

\section{Results and discussions}

\subsection{Axial compositional distributions}

Fig. 2 shows the limiting axial compositional distributions for directional solidified $\mathrm{HgCdTe}$. The two experimental curves [21], illustrate the effects of varying translation rates. The translation rates for ingots MCT-L6 and MCT-L7 were 0.310 and 0.068 $\mu \mathrm{m} / \mathrm{s}$, respectively. Solidification at the slower rate results in the build up of a much longer solute boundary layer. Hence, the stabilizing solutal forces are expected to be less during the growth. This reduced stabilizing force can lead to the increase of natural convective mixing, which results in a more uniform radial segregation. However, the axial com- positional profile never reaches a steady-state value Therefore, improved radial segregation is gained at the expense of less uniform axial composition. If the translation rate is increased, as in MCT-L6, shorter transients result in steady-state axial compositional distribution, but radial segregation increases by two orders of magnitude. These results are in qualitative agreement with the numerical calculations of Motakef $[24,25]$. His results indicate that radial segregation increases initially with decreasing Peclet mass transfer number reflecting the reduction in the mixing of the melt, which results in increased non-uniformity of melt composition at the growth interface. This suggests that improved material compositional uniformity requires sufficiently fast growth rates to produce short initial transients and a simultaneous reduction of radial segregation caused by convective effects

Fig. 3 shows the axial compositional distribution profiles for two crystals: curve MCT-D2 was obtained for growth without a magnetic field and curve MCT-4 for growth with melt stabilization by a 50 $\mathrm{kG}$ axial magnetic field. The theoretical curve based on a one-dimensional diffusion equation is also shown.

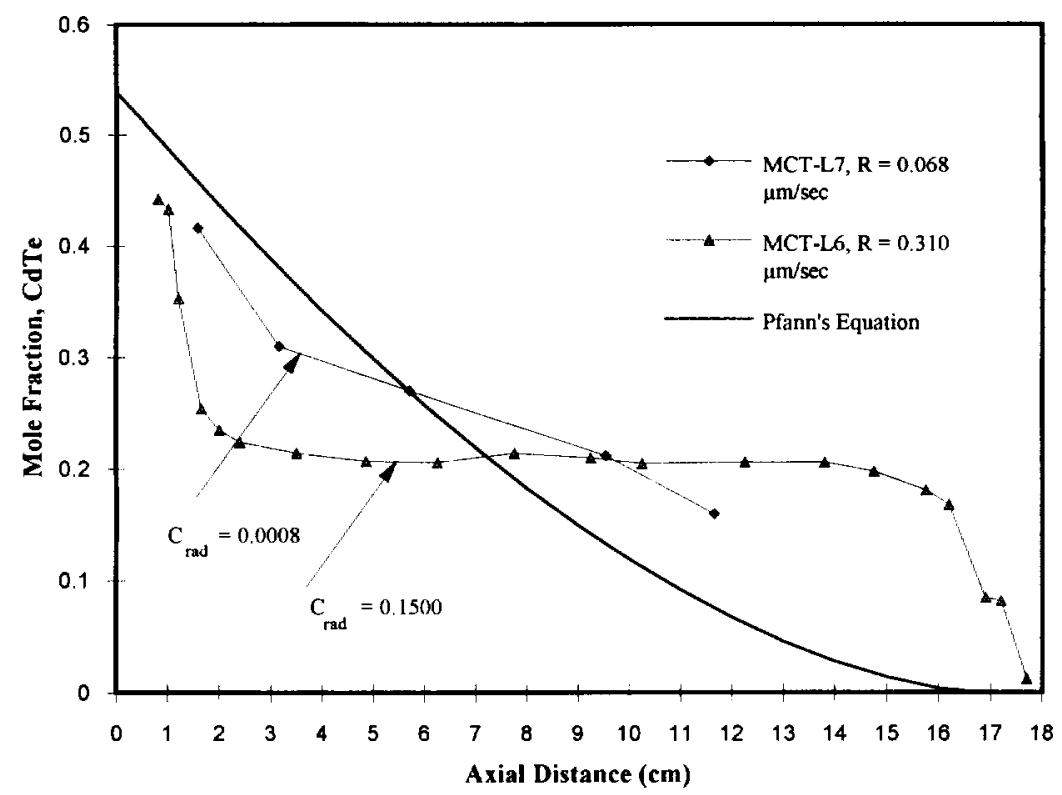

Fig. 2. Axial compositional limits of directional solidification for $\mathrm{HgCdTe}$. 


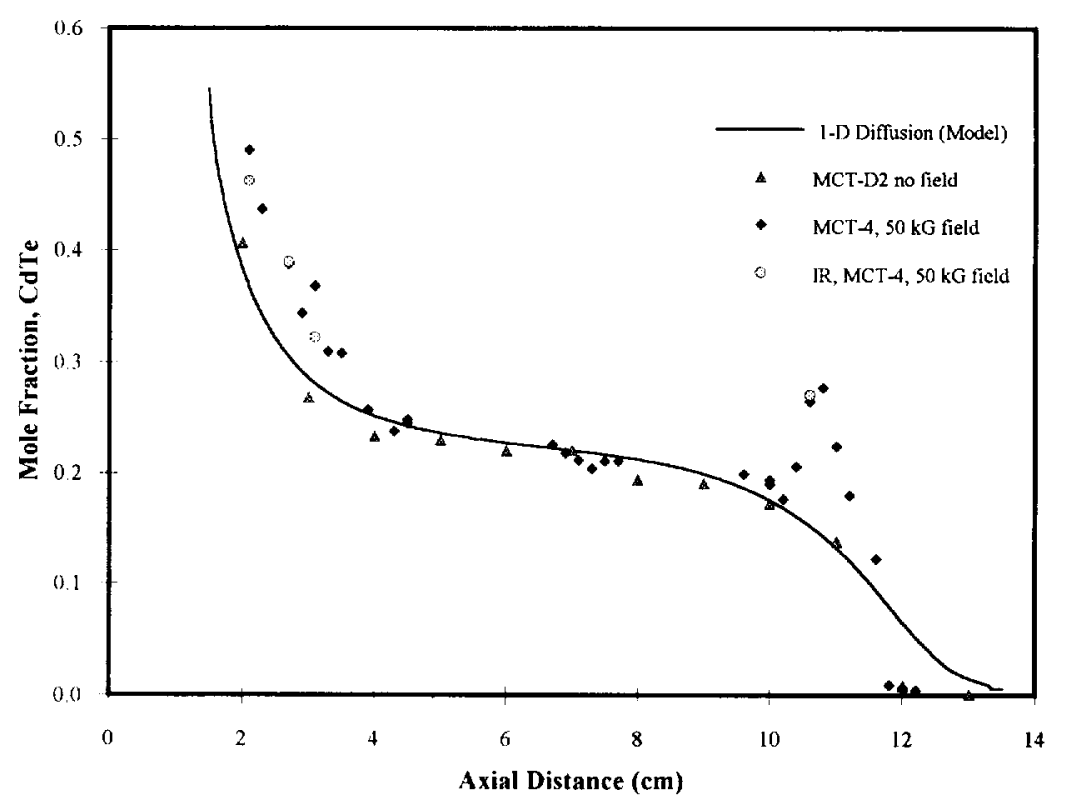

Fig. 3. Comparisen of the experimental axial compositional distribution to the one-dimensional diffusion model.

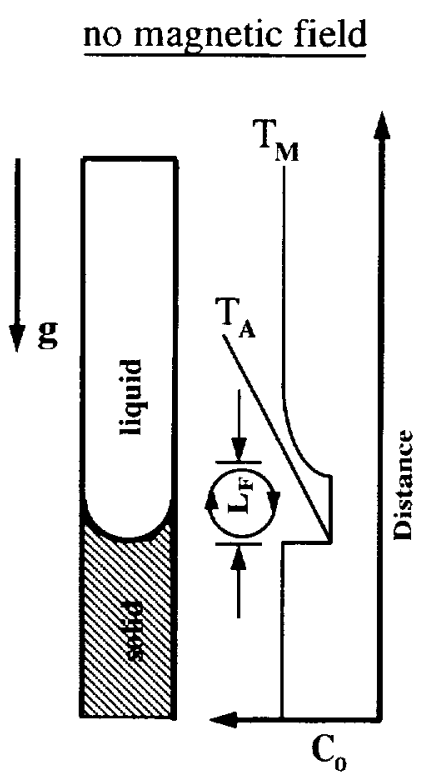

Furnace temperature, $\mathrm{T}_{\mathrm{A}}$, is larger than melt temperature, $T_{M}$. Stable growth occurs. applied magnetic field

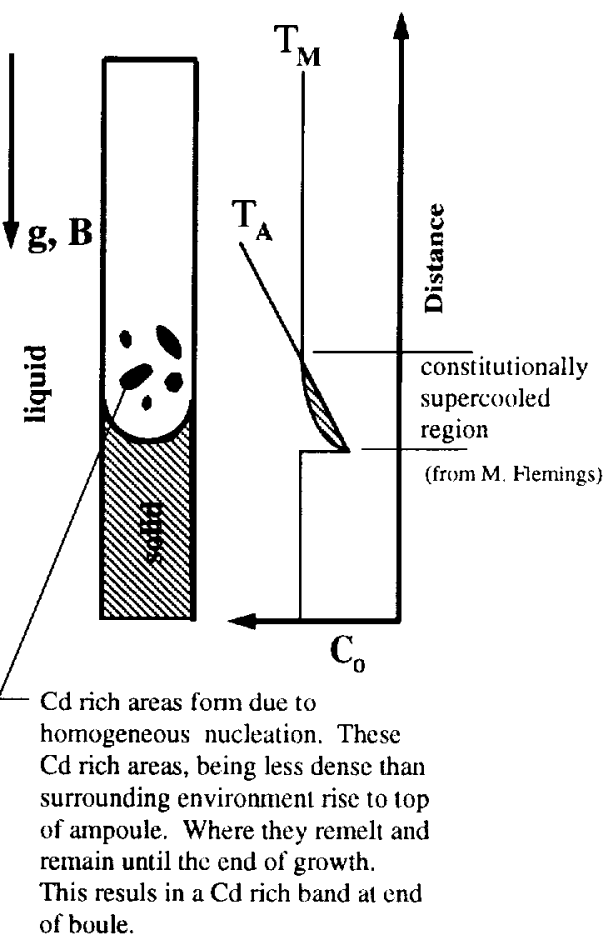

Fig. 4. Schematic representation of the convective melt flows and solute boundary layer configurations for directional solidification growth of $\mathrm{HgC}$ (Te with and without magnetic stabilization. 
The curve for MCT-D2 indicates that, as expected, during solidification in zero field the distribution of CdTe undergoes an initial transient, then a steady-state region followed by a final transient. This compares well with the curve calculated from an exact numerical solution to the one-dimensional diffusion equation for an $x=0.2$ alloy [26.27]. The curve for MCT-4 (50 kG field) shows a similar initial transient and steady-state section. However, a sharp increase in the CdTe content is observed near the last-to-freeze end just before the final transient. To ensure that this rise was not due to measurement error, IR compositional measurements were taken at various axial locations. There was excellent agreement between the two measurement techniques, see Fig. 3. This rise in CdTe content may be explained by constitutional supercooling ahead of the interface. Fig. 4, shows a schematic of the convective melt flows and solute boundary layer configurations for the no-field and field cases. In the no-field case, a region with intense convection (as compared to the growth rate) caused by radial thermal gradients is assumed to occur between a bulk of diffusion-controlled melt and the growth interface as proposed by $\mathrm{Kim}$ and Brown [28] to explain axial segregation patterns seen in $\mathrm{HgCdTe}$ crystal growth experiments by Szofran and Lehoczky [29]. Hence, the axial temperature gradient in the melt is sufficient to avoid constitutional supercooling due to the flatness of the compositional profile and normal solidification proceeds. In the case of growth in the presence of a stabilizing magnetic field, the elimination or reduction of convection allows for the build up of the diffusion-controlled solute boundary layer closer to the solid-liquid interface. As the axial temperature gradient is held constant, this stiffer solutal boundary layer produces a region in the liquid ahead of the interface that is at an actual temperature below its equilibrium liquidus temperature. Accordingly, this can lead to homogeneous nucleation of solid-phase particles, richer in $\mathrm{Cd}$ (higher $x$ ) than the bulk melt, which float upwards because their densities are less than those of the melts. This phenomenon of buoyant rising of solid particles, or Stokes migration, has been observed during vertical Bridgman-Stockbarger growth experiments of $\mathrm{HgCdTe}[30,31]$ and $\mathrm{HgCdSe}$ [32] and is consistent with the results from the growth of the MCT-4 ingot. Conclusive evidence

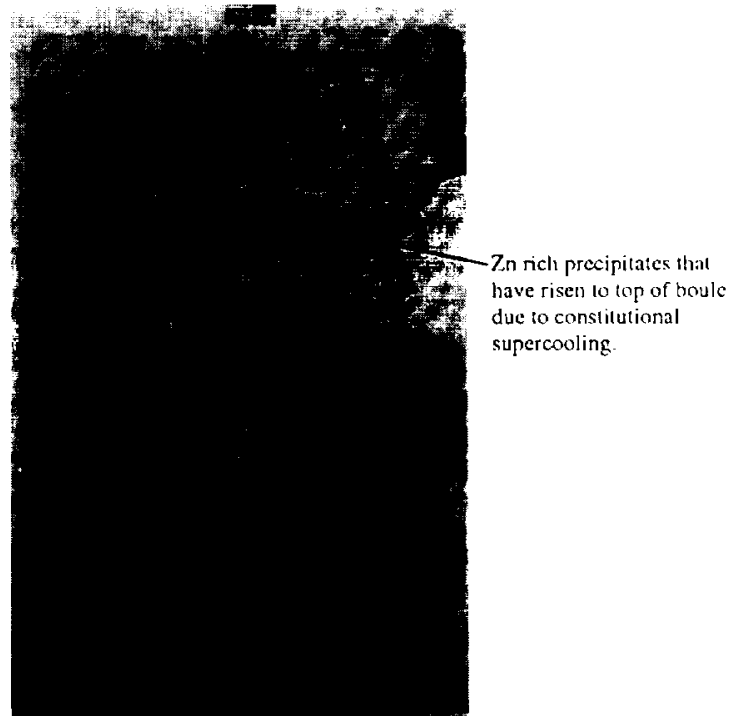

Fig. 5. Back-scatter micrograph of a quenched Hg/nTe ingol showing Zn-rich precipitates that have migrated to the top of the boule due to Stokes migration hrought athout by constituminal supercooling [3.3].

of this phenomenon is demonstrated in Fig. 5, which illustrates a back-scattering electron micrograph of a quenched $\mathrm{HgZnTe}$ ingot grown by Lehoczky it al. [33]. It clearly shows $\mathrm{Zn}$-rich precipitates that have migrated to the top of the boule due to Stokes migration resulting from constitutional supercooling.

\subsection{Radial compositional distributions.}

\subsection{Radial segregation: initial transients}

Fig. 6 shows the radial compositional variations for wafers $2.5 \mathrm{~cm}$ from the first-to-freeze portion of ingots MCT-D2 (zero field) and MCT-4 $(50 \mathrm{kG}$ field) as determined by IR transmission-edge measurements. The pattern of low $\mathrm{Cd}$ content at the center (high $\mathrm{Hg}$ content) and high Cd content along the edge of wafer \#2.2, prepared from the MCT-D2 ingot, is consistent with other results oblained previously in the absence of a magnetic field. As noted earlier, the vertical directional solidification of $\mathrm{Hg}-$ based II-VI systems is characterized by double diffusive convection and a concave (toward the solid) growth interface. Thus, the denser $\mathrm{Hg}$-rich melt tends to accumulate at the center of the crucible resulting in the radial compositional profile shown in Fig. 6a. 
Fig. $6 \mathrm{~b}$ shows the radial profile for growth in the presence of the stabilizing magnetic field. The order of magnitude improvement in radial homogeneity clearly indicates that the magnetic field was efficacious in suppressing convective effects on segregation. Fig. $6 \mathrm{c}$ shows the composition variation across the diameter of the two samples. Compositional variations in other wafers in the initial transient region show similar behavior.

\subsubsection{Radial segregation: steady-state region}

In an effort to quantify the effects of the magnetic field on the radial segregation, the experimental results were compared to the analysis of the lateral solute segregation associated with a curved solidliquid interface during steady-state unidirectional solidification of a binary alloy as derived by Coriell and Sekerka and described in detail in Ref. [34].

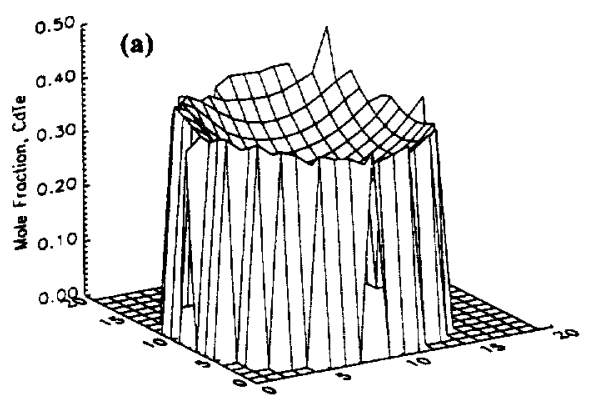

Briefly, they solved the species continuity equation for the radial solute concentration in the solid crystal at the solid-liquid interface with the assumptions of no convection in the liquid and that the solid-liquid interface could be represented by a Fourier series. Their work showed that in the limiting case, the transverse segregation in the solid is proportional to the deviation of the interface from planarity, the proportionality factor being just the product of the unperturbed concentration gradient and the distribution coefficient given by

$\Delta C / C_{0}=(k-1)\left(R / D_{\mathrm{L}}\right) \Delta \zeta$,

where $\Delta C$ is the difference in composition at the edge and center of the wafer, $k$ is the equilibrium segregation coefficient, $R$ is the translation rate and $\Delta \zeta$ is the interface deflection. These calculations are applicable for crystal growth in a stabilizing mag-

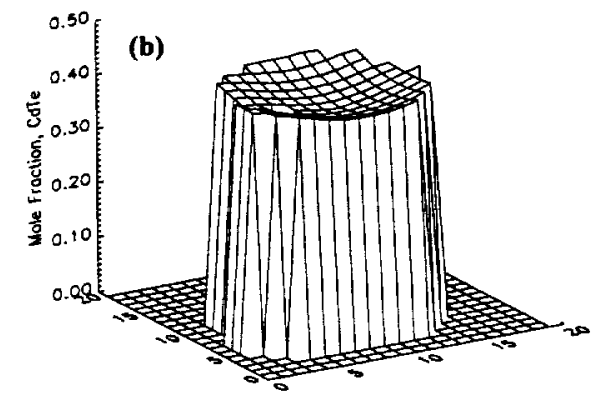

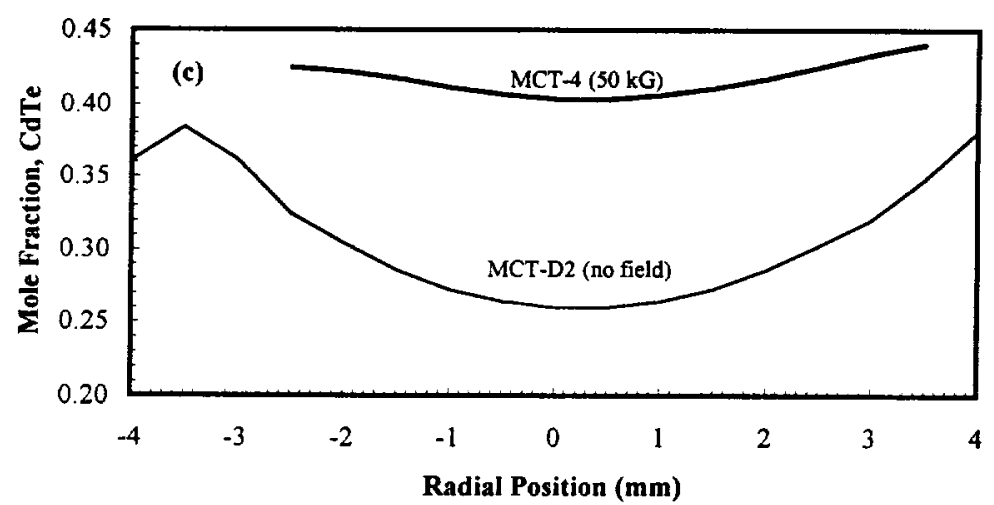

Fig. 6. Compositional profiles for (a) MCT-D2 (wafer \#2.2) $2.5 \mathrm{~cm}$ from first to freeze, grown without a magnetic field, (b) MCT-4 (wafer \#4) $2.5 \mathrm{~cm}$ from first to freeze, grown with a $50 \mathrm{kG}$ stabilizing magnetic field and (c) comparision of radial profiles. 
netic field where the field strength is sufficient to suppress convection. The solid-liquid interface deflection necessary for the calculations was determined experimentally by quenching samples with and without a magnetic field. The quenched interface obtained in the presence of a magnetic field was symmetric about the growth axis and had a maximum deflection (concave toward the solid) of 1.1 mm, which was a factor of 3 less than that obtained without the magnetic field. Similar effects on the solid-liquid interface were found in gallium-doped germanium grown in the presence of a $30 \mathrm{kG}$ axial magnetic field [35].

Fig. 7 shows a comparison of the experimental and the calculated diffusion-limited radial segregation, where the diffusion-limited regime was determined by varying the translation rate in Eq. (3.1).
For this calculation, the steady-state equilibrium segregation coefficient, $k=4.2$, was determined experimentally by measuring the compositional change across a quenched interface in the steady-state region of crystal growth. The mass diffusion coefficient, $D_{\mathrm{L}}=5.5 \times 10^{-5} \mathrm{~cm}^{2} / \mathrm{s}$, was determined by a best fit of the experimental axial composition data to the one-dimensional diffusion-limited model of Clayton et al. [36] and is consistent with the value obtained by Lehoczky et al. [21]. The figure summarizes previous data for MCT-L6 and MCT-L7, as well as, the data from MCT-D2 and MCT-4. The multiple data points for MCT-L6 and MCT-L7 are for three wafers analyzed in the steady-state region and are described in Ref. [21]. The comparison of the various experimental and calculated results strongly suggest nearly diffusion-limited growth and, thus, signifi-

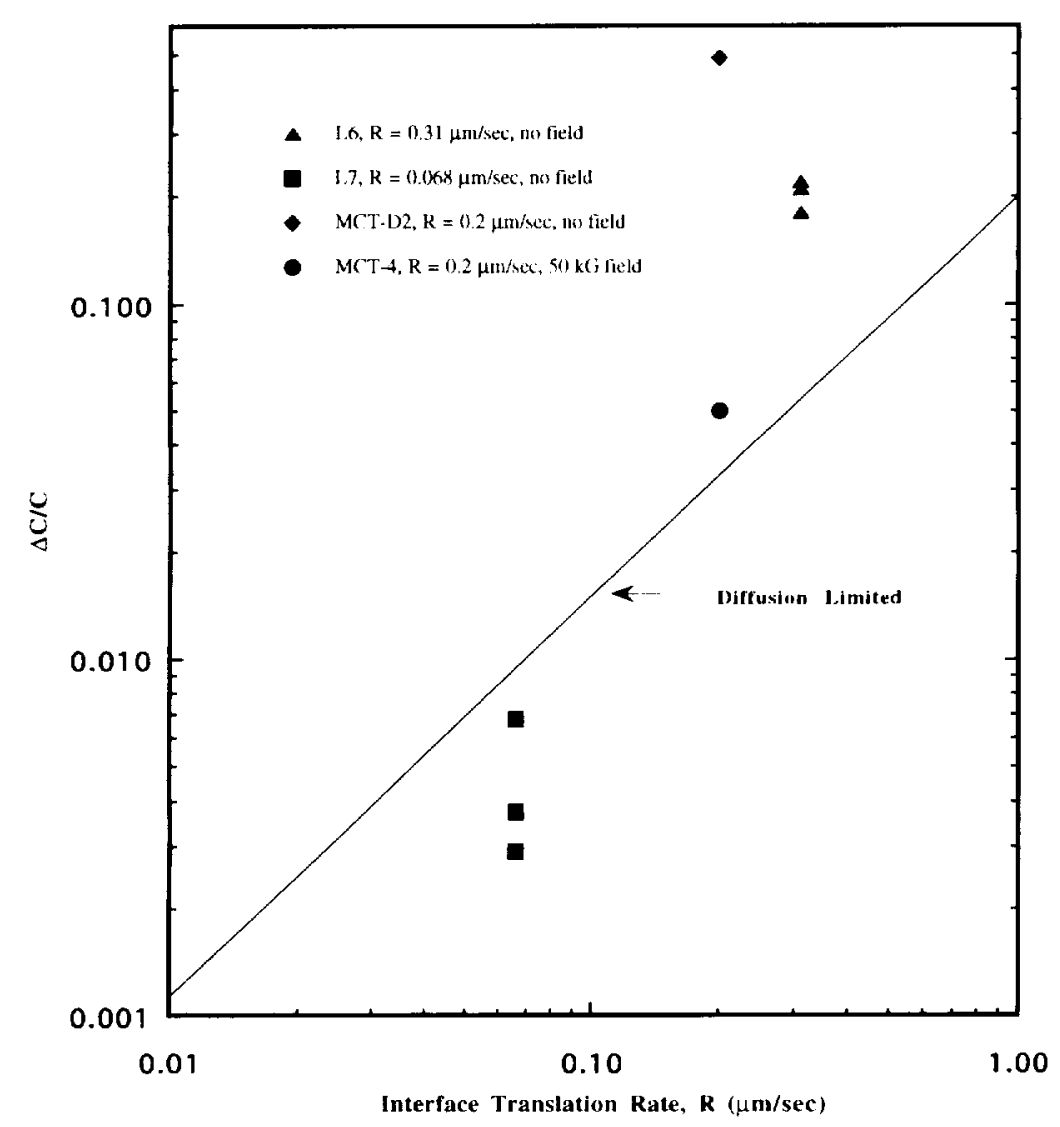

Fig. 7. Comparison of experimental and diffusion-limited radial segregation 
cantly improved compositional homogeneity can be obtained with magnetically stabilized BridgmanStockbarger growth systems.

\section{Conclusions}

An axial magnetic field was applied during crystal growth experiments in order to damp the velocity of the melt via magneto-hydrodynamic interactions. The resulting reduction in convection significantly altered the overall mass transfer and redistribution process. The primary influence of convection on mass transfer in the melt and segregation at the solid-liquid interface can be summarized as follows:

(1) The axial compositional distribution was relatively unaffected during the initial transient and steady-state growth portions of the solidification process. An abrupt rise in the CdTe content was observed near the end of the ingot and has been attributed to constitutional supercooling brought about by the magnetic suppression of convection near the solid-liquid interface, which results in an increase in the slope of the diffusion-controlled solute boundary layer.

(2) In conventional growth, the Hg-based II-VI systems are characterized by double diffusive convection and a concave growth interface. This results in the accumulation of $\mathrm{Hg}$-rich material at the center of the melt just ahead of the growth interface, which in turn increases the interface curvature because of the nature of the $\mathrm{HgTe}-\mathrm{CdTe}$ pseudo-binary phase diagram. These effects tend to enhance the radial segregation.

(3) For growth in a $50 \mathrm{kG}$ magnetic field, the convection intensity was sufficiently damped, which allowed the interface curvature and radial composition to approach diffusion-limited growth conditions.

It should be remarked that the present study indicates that the interaction of the thermal, solutal and momentum fields in $\mathrm{HgCdTe}$ systems are highly coupled. The modification of these complex interactions, through, for example, the application of a magnetic field can significantly alter the interface morphology and compositional homogeneity. Therefore, any attempts at modeling these systems should involve the fully coupled form of the governing equations.

\section{Acknowledgements}

The investigation was supported by the Microgravity Science and Applications Division of NASA. The authors wish to thank Mr. Curtis Bahr, Mr. Rens Ross, Mr. Leroy Mullaley and Mr. Don Lovell for their invaluable technical assistance in the experimental portion of this work. The authors are also indebted to Dr.'s Gillies, Su, Szofran, Volz and Motakef for their helpful discussions and suggestions during the characterization portion of this work.

\section{References}

[1] S. Chandrasekhar, Hydrodynamics and Hydromagnetic Stability (Clarendon, Oxford, 1961).

[2] W.B. Thomson, Philos. Mag. 42 (1951) 1417.

[3] B. Lehnert and N.C. Little. Tellus 9 (1957) 97.

[4] G.Z. Gershuni and E.M. Zhukhovitskii, Zh. Eksperim. Teor. Fiz. 34 (1958) 465.

[5] H.P. Utech and J.G. Early, Acta Met. 15 (1967) 1238.

[6] H.P. Utech and M.C. Flemings, J. Appl. Phys. 37 (1966) 2021.

[7] H.P. Utech and M.C. Flemings, in: Crystal Growth, Ed. H.S. Peiser (Pergamon, Oxford, 1967) p. 651.

[8] J.-C. Han, S. Motakef and P. Becla, J. Mater. Process. Manufactur. Sci. 1 (1992) 195.

[9] W.W. Fowlis, Low Gravity Sciences, Vol. 67, Science and Technology Series (1987).

[10] R.W. Series and D.T.J. Hurle, J. Crystal Growth 113 (1990) 305.

[11] D.T.J. Hurle and J.D. Hunt. The Solidification of Metals, ISI P110 (Iron and Steel Institute, 1968) p. 162.

[12] K.M. Kim, J. Electrochem. Soc. 129 (1982) 427.

[13] D.H. Matthiesen, M.J. Wargo, S. Motakef, D.J. Carlson, J.S. Nakos and A.F. Witt, J. Crystal Growth 85 (1987) 557.

[14] S. Sen, R. Lefever and W. Wilcox, J. Crystal Growth 43 (1978) 526.

[15] C.-H. Su, S.L. Lehoczky and F.R. Szofran, J. Crystal Growth 109 (1991) 392.

[16] C.H. Su, S.L. Lehoczky and F.R. Szofran, J. Appl. Phys. 60 (1986) 3777.

[17] F.R. Szofran and S.L. Lehoczky, J. Electron. Mater, 10 (1981) 1131 .

[18] J.W. Rutter and B. Chalmers, Can. J. Phys. 31 (1953) 15

[19] J.C. Woolley and B. Ray, J. Phys. Chem. Solids 13 (1960) 151 .

[20] H.A. Bowman and R.M. Schoonover, J. Res. Natl. Bur. Std. (US) $71 \mathrm{C} \mathrm{(1967)} 179$.

[21] S.L. Lehoczky, F.R. Szofran and B.G. Martin, Advanced Methods for Preparation and Characterization of Infrared Detector Materials, Part I, NASA CR-161598 (1980).

[22] F.R. Szofran, G.L.E. Perry and S.L. Lehoczky, J. Crystal Growth 86 (1988) 20. 
[23] D.C. Gillies, J. Electron. Mater. 11 (1982) 689.

[24] S. Motakef, J. Crystal Growth 102 (1990) 197.

[25] S. Motakef. J. Crystal Growth 104 (1990) 833.

[26] J.C. Clayton. Transient and Diffusion Analysis of $\mathrm{HgCdTe}$. NASA CR-162049, 1982.

[27] J.C. Clayton, M.C. Davidson, D.C. Gillies and S.L. Lehoczky, J. Crystal Growth 60 (1982) 374.

[28] D.H. Kim and R.A. Brown. J. Crystal Growth 96 (1989) 609.

[29] F.R. Szofran and S.L. Lehoczky, J. Crystal Growth 70 (1984) 349.

[30] C.H. Su, G.L.E. Perry, F.R. Szofran and S.L. Lehoczky, J. Crystal Growth 91 (1988) 20.
[31] F.R. Szofran. D. Chandra, J.-C. Wang. E.K. Cothran and S.L. Lehoczky, J. Crystal Growth 70 (1984) 343

[32] C.R. Whitsett, J.G. Broerman and C.J. Summers, Semicond Semimet. 16 (1981) 53

[33] S.L. Lehoczky, F.R, Szofran, D.C. Gillies, S.D. Cobb, C.-H. Su, Y.-G. Sha and R.N. Andrews, NASA Conf. Publ. 3272, Vol. I (1994) pp. 163-222.

[34] S.R. Coriell and R.F. Sekerka J. Crystal Growth 46 (1979) 479

[35] D.H. Matthiesen et al., J. Crystal Growth 85 (1987) 557.

[36] J.C. Clayton, M.C. Davision. D.C. Gillies and S.L. Lehoczky. J. Crystal Growth 60 (1982) 374 



\title{
Journal of Crystal Growth
}

\section{Instructions to Authors (short version)}

\section{Submission of papers}

Manuscripts (one original + two copies), should be sent to a member of the Editorial Board or preferably to an appropriate subject Associate Editor. Priority communciations should be sent to D. Elwell. News or announcements should be submitted through the Principal Editor; a duplicate should be sent directly to Elsevier Science B.V., address given below.

Original material. Submission of a manuscript implies it is not being simultaneously considered for publication elsewhere and that the authors have obtained the necessary authority for publication.

\section{Types of contributions}

Original research papers, Letters to the Editors and Priority communications are welcome. They should contain an Abstract (of up to 200 words) and a Conclusions section, which particularly in the case of theoretical papers translates the results into terms readily accessible to most readers.

As a guideline: experimental papers should not be longer than 16 double-spaced typed pages, and 8 figures + tables; for theorerical papers a maximum of 20 pages and 10 figures + tables is suggested.

Letters and Priorify communications should not be longer than 5 double-spaced typed pages, and 3 figures + tables. They will be given priority in both the refereeing and production processes. The faster production schedule may preclude sending proofs of Letters and Priority communcations to authors.

\section{Manuscript preparation}

Contributions may be written in English, French or German. They should have an abstract in English. The paper copies of the text should be prepared with double line spacing and wide margins, on numbered sheets.

Structure. Please adhere to the following order of presentation Article title, Author(s), Affiliation(s), Abstract, PACS codes and keywords, Main text, Acknowledgements, Appendices, References, Figure captions, Tables.

Corresponding author. The name, complete postal address, telephone and fax numbers and the e-mail address of the corresponding author should be given on the first page of the manuscript.

Classification codes/keywords. Please supply one to four classification codes (PACS and/or MSC) and up to six keywords of your own choice that descibe the content of your article in more detail. References. References to other work should be consecutively numbered in the text using square brackets and listed by number in the Reference list. Please refer to the more detailed instructions for examples.

\section{Illustrations}

Illustrations should also be submitted in triplicate: one master set and two sets of copies. The line drawings in the master set should be original laser printer or plotter output or drawn in black india ink, with careful lettering, large enough $(3-5 \mathrm{~mm})$ to remain legible after reduction for printing. The photographs should be originals, with somewhat more contrast than is required in the printed version. They should be unmounted unless part of a composite figure. Any scale markers should be inserted on the photograph itself, not drawn below it.

Colour plates. Figures may be published in colour, if this is judged essential by the Editor. The Publisher and the author will each bear part of the extra costs involved. Further information is available from the Publisher.

\begin{abstract}
After acceptance
Important. When page proofs of the accepted manuscripts are made and sent out to authors. this is in order to check that no undetected errors have arisen in the typesetting (or file conversion) process. At the proof stage only printer's errors may be corrected. No changes in, or additions to, the edited manuscript will be accepted. Notification. The authors will receive the final answer of acceptance or rejection from the Office of the Principal Editor and will be invited to supply an electronic version of the accepted text, if this is not already available.

Copyright transfer. In the course of the production process you will be asked to transfer the copyright of the article to the Publisher. This transfer will ensure the widest possible dissemination of information.
\end{abstract}

\section{Electronic manuscripts}

The Publisher welcomes the receipt of an electronic version of your accepted manuscript. If there is not already a copy of this (on diskette) with the joumal editor at the time the manuscript is being refereed, you will be asked to send a file with the text of the accepted manuscript directly to the Publisher by e-mail or on diskette (allowed formats $3.5^{*}$ or $5.25^{*}$ MS-DOS, or $3.5^{*} \mathrm{Mac}$ intosh) to the address given below. (When e-mailing a non-ASCII word-processor file, you should encode it, e.g. with UUENCODE or BinHex, so as to retain all formatting codes.) The name and version of the word-processing program and the type of operating system should always be indicated. Please note that no deviations from the version accepted by the Editor of the journal are permissible without the prior and explicit approval by the Editor. Such changes should be clearly indicated on an accompanying printout of the file.

\section{Author benefits}

No page charges. Publishing in Joumal of Crystal Growth is free. Free offprints. The corresponding author will receive 50 offprints free of charge. An offprint order form will be supplied by the Publisher for ordering any additional paid offprints.

Discount. Contributors to Elsevier Science joumals are entitled to a $30 \%$ discount on all Elsevier Science books.

Further information (after acceptance)

Elsevier Science B.V., J. Crystal Growth

Issue Management Physics

and Materials Science

P.O. Box 2759, 1000 CT Amsterdam

The Netherlands

Fax: +.3! $204852319 /+31204852704$

E-mail: matsci-de-f@clsevicr.nl 
